\title{
Asthma medications and disease exacerbations: an epidemiological study as a method for asthma surveillance
}

\author{
E. Van Ganse*, P.D. van der Linden*, H.G.M. Leufkens*, R.M.C. Herings*, \\ W. Vincken**, P. Ernst ${ }^{+}$
}

Asthma medications and disease exacerbations: an epidemiological study as a method
for asthma surveillance. E. Van Ganse, P.D. van der Linden, H.G.M. Leufkens, R.M.C.
Herings, W. Vincken, P. Ernst. @ERS Journals Ltd 1995. ABSTRACT: Recent experimental and epidemiological studies have suggested that outcomes of asthma are significantly influenced by treatment patterns. This study was conducted in order to investigate the links between treatment patterns in asthmatics and occurrence of disease exacerbations.

We performed a nested case-control study in a cohort of 680 asthmatics identified between 1986 and 1991 in a drug dispensing database. After validation in a pilot study, the intermittent use of oral corticosteroids was used as a proxy for asthma exacerbations. Cases with an exacerbation $(n=133)$ were pair-wise matched with controls. The type of medications used for the usual treatment of asthma were examined in relation to the risk of asthma exacerbation.

The use of oral xanthines and inhaled fenoterol but not of inhaled salbutamol, corticosteroids, cromoglycate and ipratropium bromide was associated with an increased probability of asthma exacerbation. Within the cohort, the proportion of subjects dispensed inhaled corticosteroids rose from 12 to $27 \%$ between 1986 and 1991. The proportion of subjects using inhaled bronchodilators without inhaled corticosteroids also decreased over this period of time.

The identification of markers of asthma exacerbations made it possible to link the probability of adverse outcome risk for such exacerbations with treatment patterns. This method could be useful in further development of asthma surveillance using drug dispensing databases.

Eur Respir J., 1995, 8, 1856-1860

\begin{abstract}
*Dept of Pharmacoepidemiology and Pharmacotherapy, Universiteit Utrecht, Utrecht, The Netherlands. **Respiratory Division, University of Brussels, Brussels, Belgium. +Respiratory Epidemiology Unit, McGill University, Montreal, Quebec, Canada.
\end{abstract}

Correspondence: E. Van Ganse

Dept of Pharmacoepidemiology and Pharmacotherapy

Universiteit Utrecht

PO Box 80.082

3508 TB Utrecht

The Netherlands

Keywords: asthma

nested case-control study

pharmacoepidemiology

surveillance

therapy

Received: November 71994

Accepted after revision July 111995
The prevalence of asthma, estimated to be 3-5\% in Western populations, is rising in several countries, with significant temporal and regional fluctuations in morbidity and mortality [1]. Reasons for the changes are not fully understood but environmental factors may play a critical role [2]. This rise has also been related to the pattern of use of asthma medications [3, 4]. Inhaled corticosteroid preparations are very effective when used regularly and at adequate dosage [5]. On the other hand, the optimal use of spasmolytics remains somewhat controversial. Case-control studies performed in New Zealand have suggested that fenoterol might have been implicated in the local rise of asthma mortality [6-8]. The Saskatchewan study on the risk of beta-agonists added important data for a proper interpretation of the dose-time dynamics of the use of betaagonists as a class in relation to mortality risk $[9,10]$.

In the same context, recent randomized controlled trials have suggested that regular intake of beta-agonists is associated with a poor control of asthma, leading to deterioration of lung function over time [11-13]. Regular use of these compounds also induces tolerance to their protective effects against nonspecific bronchoconstriction [14, 15] and appears to increase the bronchoconstrictive response to allergen [16]. These data suggest that the optimal use of asthma medications must be carefully tailored to patients needs. Furthermore, the introduction of new long-acting inhaled bronchodilators reinforces the need for appropriate surveillance and evaluation of the benefits and risks of asthma treatment [14]. The pharmacoepidemiological studies conducted so far, have primarily examined the associations of treatment with fatal or near fatal outcomes [6-9].

In this study, we focus on the probability of nonfatal adverse outcome (risk of disease exacerbation). Whilst there is only limited evidence so far that such exacerbations lead to increased risk for fatal or nearfatal asthma [17], they have a significant impact on the quality of life of asthmatics and the cost of care, and, therefore, research is needed to identify the determinants of these events [18]. This study was conducted in order to investigate the links between treatment patterns in asthmatics and occurrence of disease exacerbations. 


\section{Materials and methods}

\section{Data sources}

Dutch community pharmacy records ( $>95 \%$ of Dutch community pharmacies are computerized) are unique in that patients are usually assigned to a single pharmacy for reimbursement of their prescription drugs. This feature enables individual prescription drug use to be tracked. In an open population of 60,000 people, all individual users of asthma medications were identified and their dispensing history was retrieved (identification number of the patient, nature and dosage of the medications dispensed).

\section{Subjects}

The subjects studied were defined as chronic users of asthma treatment, having been dispensed at least six separate prescriptions for one or more asthma medications over the 6 year period; January 1986-December 1991. Subjects using oral corticosteroids on a continuous basis were excluded. The subjects studied were included in the base cohort on the latest of the following dates: date of the sixth asthma prescription; January 1st of the year where the subjects reached their 5th birthday; January 1st, 1986; or the date at which 180 days of complete drug dispensing history became available. Subjects left the base cohort on the earliest of the following dates: January 1st of the year of the subject's 50th birthday; the date of cessation of drug dispensing history; the date of the first occurrence of an outcome; or December 31st, 1991.

\section{Study design}

A nested case-control study was performed in a base cohort of chronic users of asthma drugs identified in a drug dispensing database. The outcome was defined as the new dispensing of oral corticosteroids, not used in the previous 3 months, and was called a "Marker of Asthma Exacerbation" (MAE). Patients belonging to the base cohort and presenting the outcome during followup were selected as cases, and the date of occurrence of a MAE was the index date. The receipt of oral corticosteroids as the outcome was validated in a pilot study investigating the relationship between this marker and the dispensing of oral antibiotics (considered as markers for respiratory tract infections), since the temporal relationship between respiratory tract infections and asthma exacerbations is well-established [19].

Matched controls were selected randomly among the base cohort patients who did not use either oral corticosteroids (new dispensing, according to the definition of MAE) or a new treatment with at least three different asthma drugs. New treatments are those including at least two asthma drugs not used in the previous 3 months. Matching was performed for the following variables: gender; age at index date $( \pm 5 \mathrm{yrs})$; date of entry prior to the index date within 3 months of the case.

\section{Drug exposure}

Dispensing of asthma medications by the pharmacists were compared in both cases and controls for the 6 months preceding the index date, for the following medications: inhaled salbutamol, inhaled fenoterol, inhaled ipratropium bromide and oral xanthines as bronchodilators, inhaled cromoglycate, and inhaled corticosteroids. Exposure to each of these was considered as present or absent without regard to dose or detailed formulation.

For the cohort as a whole, for each of the following classes of medication: inhaled beta-agonists, inhaled corticosteroids, inhaled ipratropium bromide, inhaled cromoglycate and oral xanthines, proportions of users were determined for each calendar year from 1986 to 1991, arbitrarily assuming that the population studied was constant. Concomitant use of bronchodilators and inhaled corticosteroids was assessed by determining the medications dispensed during the month of September of each year, and assuming their use was simultaneous if dispensed within the same month.

\section{Data analysis}

Odds ratios (OR) were computed for the risk of disease exacerbation following different asthma drug exposure applying conditional logistic regression. Adjusted OR were computed, accounting for the simultaneous use of several asthma medications and, in a secondary analysis, for the total number of separate (asthma drugs) prescriptions in the six months before the index date $(\geq 3$ prescriptions; and $<3$ prescriptions). This information was considered as a marker for severity to allow adjustment for possible differences in severity between cases and controls.

\section{Results}

A total of 6,987 patients (12\% of the population) who received at least one asthma medication between January 1985 and December 1991 were identified. After application of the eligibility criteria for chronic use (six or more separate prescriptions), 680 patients remained in the base cohort (1.1\% of the population). A total of 133 patients with an asthma exacerbation were matched with controls, making up 133 case-control pairs (table 1). Comparative data on the 133 case-control pairs demonstrated the efficacy of the matching, with similar mean age ( 31 yrs for the cases versus 32 yrs for the controls). There were 65 male and 68 female pairs. Follow-up time was also comparable in the two groups.

Table 1. - Description of cases and controls (133 matched pairs)

\begin{tabular}{lcc}
\hline Variable & Cases & Controls \\
\hline Age yrs* & $32(6-49)$ & $32(6-50)$ \\
Gender F/M & $68 / 65$ & $68 / 65$ \\
Days of follow-up* & $1,420(118-1,998)$ & $1,291(68-2,003)$ \\
\hline
\end{tabular}

*: values are presented as mean, and range in parenthesis. 
Table 2. - Risk of disease exacerbation in different exposure groups

\begin{tabular}{lcccr}
\hline Exposure & $\begin{array}{c}\text { Cases } \\
\%\end{array}$ & $\begin{array}{c}\text { Controls } \\
\%\end{array}$ & $\begin{array}{c}\text { Crude OR } \\
(95 \% \mathrm{CI})\end{array}$ & $\begin{array}{c}\text { Adjusted OR } \\
(95 \% \mathrm{CI})\end{array}$ \\
\hline Inhaled corticosteroids & 46 & 23 & $2.2(1.3-3.9)$ & $2.1(1.0-4.3)$ \\
Inhaled fenoterol & 15 & 3 & $5.0(1.7-14.6)$ & $10.0(2.6-38.2)$ \\
Inhaled salbutamol & 53 & 50 & $1.2(0.7-2.0)$ & $1.1(0.6-2.2)$ \\
Ipratropium bromide & 18 & 8 & $2.6(1.2-5.5)$ & $1.8(0.7-4.7)$ \\
Cromoglycate & 19 & 18 & $1.1(0.6-2.0)$ & $0.9(0.4-1.9)$ \\
Oral xanthines & 36 & 10 & $4.9(2.4-10.0)$ & $2.9(1.2-6.9)$ \\
\hline
\end{tabular}

*: adjusted for other exposures with conditional logistic regression. OR: odds ratios; $95 \%$ CI: $95 \%$ confidence interval.

In the pilot phase investigating the relationship between the use of oral antibiotics and the proxy outcome, a crude OR of 13.5 (95\% confidence interval $(95 \% \mathrm{CI}) 3.2$ and 56.7) was obtained. There was, thus, a significant relationship between the use of oral antibiotics and the subsequent dispensing of oral corticosteroids.

When crude ORs were computed for the risk linked with the use of asthma medications, two bronchodilating agents were associated with a large increase in risk: inhaled fenoterol and oral xanthines (table 2). The crude risk was also increased with ipratropium bromide $(\mathrm{OR}=2.6$; 95\% CI 1.2-5.5) and inhaled corticosteroids ( $\mathrm{OR}=2.2$; 95\% 1.3-3.9). After adjustment, taking into account the other treatments used by the patients and the number of separate prescriptions dispensed before index date, only fenoterol and oral xanthines remained significantly associated with an increased risk for exacerbations.

Among all patients from the base cohort during the years 1986-1991, there was an increase in the use of inhaled beta-agonists and of inhaled corticosteroids, but no change in the use of cromoglycate and ipratropium bromide, and a tendency to decreased use of oral xanthines (fig. 1). For patients using inhaled beta-agonists, the proportion also using inhaled corticosteroids rose from 18 to $35 \%$ between 1986 and 1991; for patients using oral xanthines, that proportion rose from 30 to $42 \%$, whilst for patients using ipratropium bromide, it rose from 25 to $47 \%$ (fig. 2).

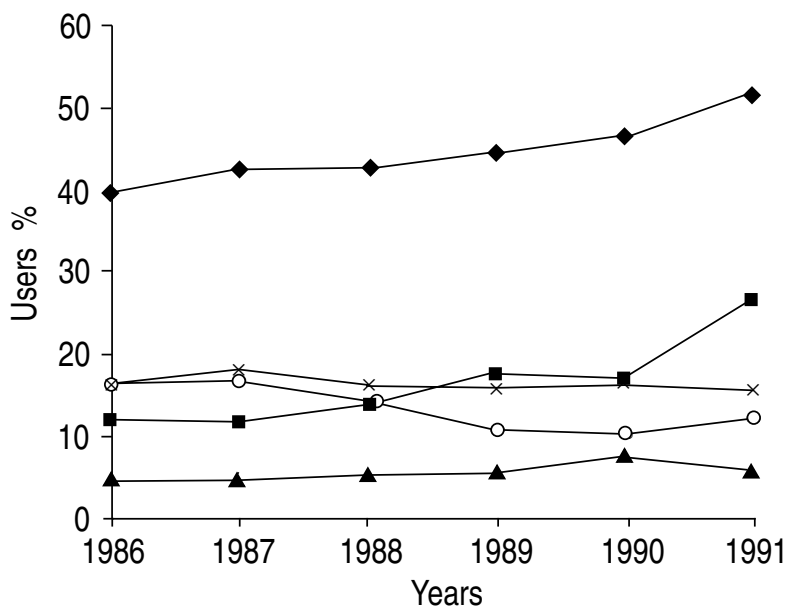

Fig. 1. - Use of asthma medications among Dutch asthma patients between 1986 and $1991(\mathrm{n}=680)$. $\longrightarrow$ : inhaled beta-agonists; $\square$ : inhaled corticosteroids; $\longrightarrow$ : ipratropium bromide; $\longrightarrow$ : sodium cromoglycate; - - : oral xanthines.

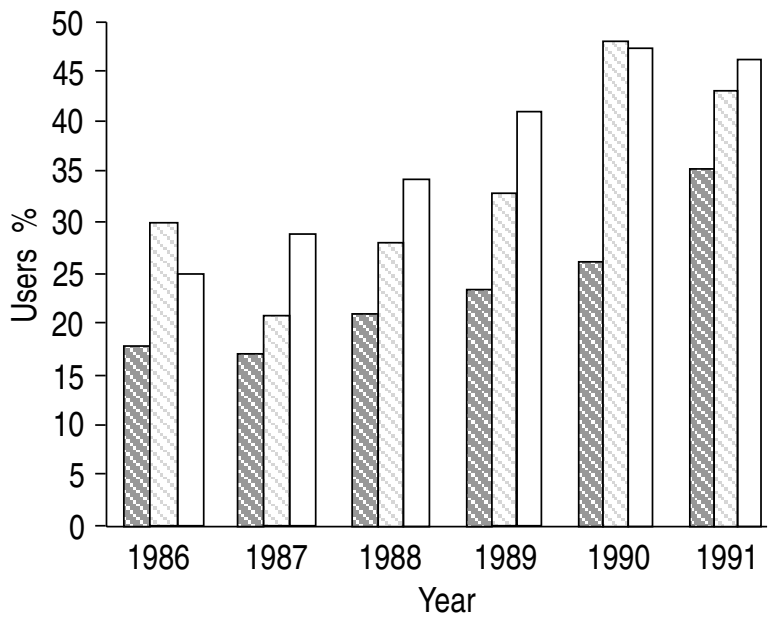

Fig. 2. - Intake of inhaled corticosteroids (ICS) among bronchodilator users. $\square$ : inhaled beta-agonists +ICS; $\square$ : oral xanthines + ICS ; $\square$ : ipratropium bromide + ICS.

\section{Discussion}

Starting from a population of 60,000 inhabitants, a base cohort of 680 asthmatic patients requiring regular therapy could be identified, i.e. a prevalence of $1.1 \%$. This is compatible with surveys on the prevalence of asthma in Western countries, taking into account the inclusion in the present study only of subjects aged 5-50 yrs and requiring medication at least intermittently. In this population, we found a 10 fold increased probability of adverse outcome in patients on fenoterol, and a threefold rise of this probability in patients using oral xanthines. Other exposures to asthma drugs were not associated with our measure of asthma exacerbation.

The interpretation of our results depends upon the validity of the proxy measurement of disease exacerbation. We think the choice of oral corticosteroids to be appropriate since it is a fairly specific marker of exacerbations among asthmatics not taking these regularly, and the other indications for intermittent use of oral corticosteroids are unusual in this age and disease group. Oral corticosteroids are also a rather sensitive indicator for exacerbations, since many prescribers tend to use them as a first-line treatment for these conditions. Finally, since they are prescribed in an acute situation, oral corticosteroids may be assumed to be used shortly after dispensing, making the accurate identification of the index date possible. 
The exclusion of chronic users of oral corticosteroids in our study would not induce a bias. Such patients have the most severe forms of disease, and including them would enhance the probability or the size of any indication bias for exposure to defined asthma medications. Chronic use of oral corticosteroids is also more common among chronic obstructive pulmonary disease (COPD) patients, and exclusion of this pattern of exposure should result in an increased proportion of asthmatics in the cohort and an increased specificity of the marker for asthma exacerbations.

Patients using at least two new asthma medications were also not allowed as controls. Besides the prescription of oral corticosteroids, asthma treatment extensions - addition of one or more new medications to the usual treatment - also suggests an exacerbation [17]. The validity of MAE was evaluated in a pilot phase of the study, investigating the relationship between this use and the occurrence of a respiratory tract infection (RTI), as identified by the dispensing of oral antibiotics. RTIs are, indeed, frequently treated with oral antibiotics and are frequent precursors of an asthma exacerbation. The choice of oral antibiotics as indicators of RTIs was made despite the fact that this is not the most appropriate therapy, since many RTIs are of viral origin $[19$, 20].

The results from this nested case-control study should be interpreted in the light of the dynamics of, and the variability in, drug exposure [21]. The main results are in good agreement with the data from other studies investigating the effect of medications on the control of asthma or their link with severe outcomes [12]. Several investigators have found an excess probability of adverse outcome for fenoterol as compared to salbutamol, even when the comparison was carried out on a weight equivalent basis [9]. Such a difference between two very similar compounds could result if fenoterol was preferentially prescribed to more severe asthmatics. The occurrence of a susceptibility bias may never be totally excluded; it may occur when the most severe patients are prescribed the most potent medications [10].

In this study, the number of separate asthma prescriptions in the 6 months before the index date has been used as a proxy for severity. The rationale for this choice is that intensity of use of medications, apart from their nature or the identity of prescribers, can be considered as a signal of concern from the patient experiencing insufficient control of the disease. When ORs are adjusted with this marker for severity, inhaled fenoterol and oral xanthines are still linked to more frequent occurrence of the outcome. In our view, this tends to demonstrate the limits of observational designs, where bias by indication can never be excluded as an explanation for the results [22]. An alternative explanation is that the regular use of fenoterol gives rise to worsening asthma, thus leading to an increase in hospitalization. While the study by SEARs et al. [11] has suggested this possibility, this has not been confirmed by others [23], and is unlikely to be limited to fenoterol. The prescription of fenoterol to more severe asthmatics is a more likely explanation, in view of the fact that channelling, i.e. preferential prescription of fenoterol to more severe asthmatics, has been described in the Dutch asthmatic population [24].

Among anti-inflammatory drugs, the use of inhaled corticosteroids during the 6 months preceding the index date was associated with a slightly increased OR; this probability losing significance when the adjusted OR was computed. This finding could suggest that inhaled corticosteroids would not protect patients against the occurrence of exacerbations, a result which is in contrast to previous outcomes demonstrating the efficacy of these medications in controlling asthma and in reducing the incidence of exacerbations $[25,26]$. A possible explanation might be the definition of exposure in the present study: any dispensing in the 6 months preceding the index date. Indeed, in contrast to inhaled beta-agonists, that are used shortly after purchase, inhaled corticosteroids tend to be kept longer by the patients, except when regular use - the rational use - is recommended by the prescriber. The time-dosing patterns of inhaled medications were not reliably recorded in the database, and a distinction was, thus, not possible between regular and irregular use. The study of subgroups of regular recipients of different dosages would usefully complement the present data [27]. Other explanations for the lack of protective effects of inhaled corticosteroids include the presence of another channelling phenomenon, or an excessive confidence in the effects of the medication, with insufficient care to avoid risk factors, such as exposure to aeroallergens.

Finally, the presence of a sample distortion bias should be considered. The most severe cases of exacerbation have a higher chance of becoming hospitalized, thus escaping from the database, which did not contain information on the treatment used during the hospitalization. Nevertheless, such a bias tends to decrease the computed probability of adverse outcome and would not modify the present conclusions. Information or misclassification bias was not a risk in this study, since the information regarding exposure originated from highly reliable computerized dispensing data. In The Netherlands, most patients are registered in one pharmacy. There is also a low probability that drugs dispensed were not used, since the indications are quite specific and precautions were taken to include only patients with regular use. The possibility remains that the patients used the medications at a distant time interval from the dispensing date, but such a risk was partly addressed by the choice of a long period of exposure - 6 months - to assess the use, and by the categorical classification of exposure.

This study also allowed us to look at the use of asthma medications in a sample of the Dutch population between 1986 and 1991. There was a tendency to increased use of inhaled beta-agonists and inhaled corticosteroids, in contrast to decreased use of oral xanthines and little or no change for ipratropium bromide and cromoglycate. It is interesting to note that similar changes have been found in a study performed in Canada during the years 1985-1990 [28]. Study of the concomitant use confirmed previous findings, with a tendency to increased co-use of inhaled corticosteroids and all classes of bronchodilators. 
In summary, the identification of markers of asthma exacerbations made it possible to link the probability of this adverse outcome with treatment patterns and to identify co-factors. Among bronchodilating agents, only inhaled fenoterol and oral xanthines were associated with an increased risk of exacerbations. Anti-inflammatory agents studied - inhaled corticosteroids and cromoglycate - were not linked with that outcome. The study also confirmed that significant changes occurred in The Netherlands regarding the patterns of asthma treatments between 1986 and 1991, with a marked increase in the use of inhaled corticosteroids. The method applied in this study could be useful in further development of pharmacoepidemiologic research of asthma. Forthcoming studies will be performed in larger populations to identify patients at risk for other outcomes (e.g. hospital admission), to make comparisons between therapeutic regimens, and to assess cost-effectiveness of treatments.

\section{References}

1. Sears MR. Worldwide trends in asthma mortality. Bull Int Union Tuberc Lung Dis 1991; 66 : 79-83.

2. Burney PGJ. Why study the epidemiology of asthma? Thorax 1988; 43: 425-428.

3. Sears MR, Rea HH, Fenwick J. Seventy five deaths in asthmatics prescribed home nebulizers. Br Med J 1987; 294: 477-480.

4. Wahedna I, Wong CS, Wisniewski AFZ, Pavord ID, Tattersfield AE. Asthma control during and after cessation of regular beta ${ }_{2}$ - agonist treatment. Am Rev Respir Dis 1993; 148: 707-712.

5. Guidelines on the management of asthma. Woodhead M, ed. Thorax 1993; 48: S1-S24.

6. Crane J, Flatt A, Jackson R, et al. Prescribed fenoterol and death from asthma in New Zealand, 1981-1983: case control study. Lancet 1989; 1: 917-922.

7. Grainger J, Woodman K, Pearce N, et al. Prescribed fenoterol and death from asthma in New Zealand, 1987: a further case-control study. Thorax 1991; 46 : 105111.

8. Pearce N, Grainger J, Atkinson M, et al. Case-control study of prescribed fenoterol and death from asthma in New Zealand, 1977-1981. Thorax 1990; 45: 170175.

9. Spitzer WO, Suissa S, Ernst P, et al. The use of betaagonists and the risk of death and near death from asthma. $N$ Engl J Med 1992; 326: 501-506.

10. Ernst P, Habbick B, Suissa S, et al. Is the association between inhaled beta-agonist use and life-threatening asthma because of confounding by severity? Am Rev Respir Dis 1993; 148: 75-79.

11. Sears MR, Taylor DR, Print CG, et al. Regular inhaled beta-agonist treatment in bronchial asthma. Lancet 1990; 336 : 1391-1396.
12. Taylor DR, Sears MR, Herbison GP, et al. Regular inhaled beta-agonist in asthma: effects on exacerbations and lung function. Thorax 1993; 48: 134-138.

13. Van Schayck CP, Dompeling E, Van Herwaarden CL, et al. Bronchodilator treatment in moderate asthma or chronic bronchitis: continuous or on demand? A randomised controlled study. Br MedJ 1991; 303: 1426-1431.

14. Cheung D, Timmers MC, Zwinderman AH, Bel EH, Dijkman JH, Sterk PJ. Long-term effects of a long-acting beta $_{2}$-adrenoceptor agonist, salmeterol, on airway hyperresponsiveness in patients with mild asthma. $N$ Engl J Med 1992; 327: 1198-1203.

15. O'Connor BJ, Aikman SL, Barnes PJ. Tolerance to the nonbronchodilator effects of inhaled beta 2 -agonists in asthma. N Engl J Med 1992; 327: 1204-1208.

16. Cockcroft DW, McParland CM, Britto S., Swystun VA, Rutherford BC. Regular inhaled salbutamol and airway responsiveness to allergen. Lancet 1993; 342: 833-837.

17. Rea HH, Scragg R, Jackson R, Beaglehole R, Fenwick J, Sutherland DC. A case-control study of deaths from asthma. Thorax 1986; 41: 833-839.

18. Juniper EF, Guyatt GH, Ferrie PJ, Griffith LE. Measuring quality of life in asthma. Am Rev Respir Dis 1993; 147: 832-838.

19. Beasley R, Coleman ED, Hermon Y, Holst PE., O'Donnell TV, Tobias MS. Viral respiratory tract infections and exacerbations of asthma in adult patients. Thorax 1988; 43: 679-683.

20. Trigg CJ, Davies RJ. Infection, asthma and bronchial hyperresponsiveness. Respir Med 1993; 87: 165-167.

21. Leufkens HG, Urquhart J. Variability in patterns of drug usage. J Pharm Pharmacol 1994; 46: 433-437.

22. Barrett TE, Ström BL. Inhaled beta-adrenergic receptor agonists in asthma: more harm than good? Am Respir Crit Care Med 1995; 151: 574-577.

23. Chapman KR, Keslan S, Szalai JP. Regular vs as-needed inhaled salbutamol in asthma control. Lancet 1994; 343: 1379-1382.

24. Petri H, Urquhart J, Herings R, Bakker A. Characteristics of patients prescribed three different inhalational beta 2 agonists: an example of the channeling phenomenon. Post Market Surveill 1991; 5: 57-66.

25. Kerstjens HAM, Brand PLP, Hughes MD, et al. A comparison of bronchodilator therapy with or without inhaled corticosteroid therapy for obstructive airways disease. $N$ Engl J Med 1992; 327: 1413-1419.

26. Van Essen-Zandvliet EE, Hughes MD, Waalkens HJ, Duiverman EJ, Pocock SJ, Kerrebijn KF. Effects of 22 months of treatment with inhaled corticosteroids and/or beta $_{2}$-agonists on lung function, airway responsiveness, and symptoms in children with asthma. Am Rev Respir Dis 1992; 146: 547-554.

27. Ernst P, Spitzer WO, Suissa S, et al. Risk of fatal and near-fatal asthma in relation to inhaled corticosteroid use. J Am Med Assoc 1992; 268: 3462-3464.

28. Kesten S, Rebuck AS, Chapman KR. Trends in asthma and chronic obstructive pulmonary disease therapy in Canada, 1985 to 1990. J Allergy Clin Immunol 1993; 92: 499-506. 